\title{
Cell number regulator genes in Prunus provide candidate genes for the control of fruit size in sweet and sour cherry
}

\author{
P. De Franceschi - T. Stegmeir • A. Cabrera $\cdot$ E. van der Knaap \\ U. R. Rosyara $\cdot$ A. M. Sebolt $\cdot$ L. Dondini $\cdot$ E. Dirlewanger $\cdot$ \\ J. Quero-Garcia · J. A. Campoy · A. F. Iezzoni
}

Received: 7 January 2013/Accepted: 18 April 2013/Published online: 30 April 2013

(C) The Author(s) 2013. This article is published with open access at Springerlink.com

\begin{abstract}
Striking increases in fruit size distinguish cultivated descendants from small-fruited wild progenitors for fleshy fruited species such as Solanum lycopersicum (tomato) and Prunus spp. (peach, cherry, plum, and apricot). The first fruit weight gene identified as a result of domestication and selection was the tomato $F W 2.2$ gene. Members of the $F W 2.2$ gene family in corn (Zea mays) have been named CNR (Cell Number Regulator) and two of them exert their effect on organ size by modulating cell number. Due to the critical roles
\end{abstract}

Electronic supplementary material The online version of this article (doi:10.1007/s11032-013-9872-6) contains supplementary material, which is available to authorized users.

P. De Franceschi · L. Dondini

Dipartimento di Scienze Agrarie, Università degli Studi

di Bologna, Bologna, Italy

T. Stegmeir · U. R. Rosyara · A. M. Sebolt ·

A. F. Iezzoni $(\square)$

Michigan State University, East Lansing, MI, USA

e-mail: iezzoni@msu.edu

\section{A. Cabrera $\cdot$ E. van der Knaap}

Ohio Agricultural Research and Development Center,

The Ohio State University, Wooster, OH, USA

E. Dirlewanger · J. Quero-Garcia · J. A. Campoy

INRA, UMR 1332 de Biologie du Fruit et Pathologie,

33140 Villenave d'Ornon, France

E. Dirlewanger · J. Quero-Garcia · J. A. Campoy University of Bordeaux, UMR 1332 de Biologie du Fruit et Pathologie, 33140 Villenave d'Ornon, France of $F W 2.2 / C N R$ genes in regulating cell number and organ size, this family provides an excellent source of candidates for fruit size genes in other domesticated species, such as those found in the Prunus genus. A total of $23 F W 2.2 / C N R$ family members were identified in the peach genome, spanning the eight Prunus chromosomes. Two of these CNRs were located within confidence intervals of major quantitative trait loci (QTL) previously discovered on linkage groups 2 and 6 in sweet cherry (Prunus avium), named PavCNRI2 and PavCNR20, respectively. An analysis of haplotype, sequence, segregation and association with fruit size strongly supports a role of PavCNRI2 in the sweet cherry linkage group 2 fruit size QTL, and this QTL is also likely present in sour cherry ( $P$. cerasus). The finding that the increase in fleshy fruit size in both tomato and cherry associated with domestication may be due to changes in members of a common ancestral gene family supports the notion that similar phenotypic changes exhibited by independently domesticated taxa may have a common genetic basis.

Keywords Cell number regulator · Fruit size · Marker-assisted selection · Cherry · Domestication · Prunus

\section{Introduction}

Cultivated fruit and vegetable crops often bear little phenotypic resemblance to their wild ancestors (Paran 
and van der Knaap 2007). The change from a huntergatherer to an agricultural lifestyle, starting approximately $10,000-13,000$ years ago, led to the domestication of plants from wild progenitors, leading to plants better adapted to cultivation and human use. The resulting selection of alleles from wild progenitors, many of which may have arisen as spontaneous mutations, led to dramatic changes in plant traits associated with the domestication syndrome (Hammer 1984), including increases in the size of edible organs such as fleshy fruit.

Domestication-associated increases in fleshy fruit size occurred in diverse plant families such as the Cucurbitaceae (Nuñez-Palenius et al. 2008; Esteras et al. 2011; Paris et al. 2012), Solanaceae (Tanksley 2004; Paran and van der Knaap 2007; Wang et al. 2008; Meyer et al. 2012) and Rosaceae (Miller and Gross 2011). However, the understanding of the genetic changes that resulted in this fruit size increase between domesticates and their small-fruited wild relatives is most advanced in tomato (Solanum lycopersicum L.) (Grandillo et al. 1999; Brewer et al. 2007; Paran and van der Knaap 2007; Causse et al. 2007; Gonzalo and van der Knaap 2008). One of the major tomato fruit size quantitative trait loci (QTL) explained approximately $30 \%$ of the fruit weight variation in interspecific populations (Alpert and Tanksley 1996). The underlying gene, FW2.2, was identified by map-based cloning and shown to be expressed in the early stages of fruit development and to modulate cell proliferation (Frary et al. 2000; Cong et al. 2002). FW2.2 copy number and expression levels were negatively correlated with cell division activity in the early stages of fruit development; therefore, $F W 2.2$ was proposed to act as a negative regulator of cell number (Liu et al. 2003). Members of the $F W 2.2$ gene family have been identified in other plants such as avocado fruit (Persea americana Mill.) (Dahan et al. 2010) and soybean root nodules [Glycine $\max$ (L.) Merr.] (Libault et al. 2010), where they are hypothesized to control cell number. In maize (Zea mays L.), a genome-wide search for $F W 2.2$ family members led to the identification of a family of 13 genes, named cell number regulators (CNR; Guo et al. 2010). The over-expression of $Z m C N R 1$ resulted in a reduction of overall plant stature, by acting as a negative cell number regulator in multiple tissues, while $Z m C N R 2$ also affected organ and plant size (Guo et al. 2010).
$F W 2.2$ and $C N R$ genes share a cysteine-rich domain named PLAC8, first characterized in mammalian placenta (Galaviz-Hernandez et al. 2003), whose function is unknown. In addition to their involvement in the regulation of cell proliferation, members of the PLAC8 family have been characterized as membranebound proteins capable of interacting with metal cations. Among these, PCR (Plant Cadmium Resistance) genes are involved in extrusion of cadmium and zinc ions through the plasma membrane, contributing to heavy metal detoxification (Song et al. 2004, 2010); and MCA (Mid1-Complementing Activity) genes were identified for their ability to restore calcium uptake in yeast cells lacking the Mid1/Cch1 channel (Yamanaka et al. 2010).

The Prunus genus in the Rosaceae family includes many fleshy-fruited species such as peach [Prunus persica (L.) Batsch], diploid sweet cherry (Prunus avium L.), tetraploid sour cherry (P. cerasus L.), plum (P. domestica L. and $P$. salicina Lindl.) and apricot $(P$. armeniaca $\mathrm{L}$.) that are cultivated in temperate regions throughout the world. Cultivars that consistently produce large fruits are critical for grower profitability. For example, for the fresh-market sweet cherry, fruit size is the main criterion by which the fruit is graded for sale (Whiting et al. 2006). Therefore, obtaining new large-fruited cultivars is a major breeding goal. However, improvement of Prunus fruit tree crops has lagged behind annual crops, in part due to the long juvenile phase that can last up to 5 years and significantly hampers the expeditious phenotypic evaluations for fruit quality traits. Therefore, knowledge of markers and genes associated with fruit size in Prunus species has the potential to significantly increase the efficiency of breeding large-fruited cultivars, as it would allow the early elimination of seedlings that have the potential of bearing fruit that is smaller than the target size threshold. This knowledge would also greatly facilitate the use of small-fruited wild germplasm, as it would reduce the number of generations needed to obtain the commercial fruit size needed for a new cultivar.

In sweet cherry, the wild, landrace and modern varieties typically exhibit fruit weights of $2 \mathrm{~g}, 6 \mathrm{~g}$, and up to $14 \mathrm{~g}$, respectively. Although fruit weight in Prunus behaves as a quantitative trait like that of tomato fruit weight, a high portion of the phenotypic variation is explained by a few major QTL (Zhang et al. 2010). In a cross between a wild mazzard, New 
York 54, and a landrace sweet cherry, Emperor Francis, QTL were identified on linkage groups 2 (G2) and 6 (G6), with the G2 QTL postulated to affect fruit size by controlling mesocarp cell number (Zhang et al. 2010). In tetraploid sour cherry, whose ancestral sub-genomes are derived from both the diploid sweet cherry and the wild tetraploid ground cherry $(P$. fruticosa Pall.), a G2 QTL was identified in a similar linkage group position (Wang et al. 2000).

The $C N R$ gene family provides an excellent source of candidate genes for investigating the genetic control of fruit size in Prunus. Its critical role of controlling fruit size by increasing cell number and organ size is demonstrated by $F W 2.2$ in tomato (Frary et al. 2000), and $Z m C N R 1$ and $Z m C N R 2$ in maize (Guo et al. 2010). Using the peach genome v.1.0 sequence released by the International Peach Genome Initiative (GDR database: http://www.rosaceae.org/species/prunus_persica/gen ome_v1.0), the identification of the CNR family in Prunus is possible. Because of the high level of synteny between peach and the other Prunus species (Dirlewanger et al. 2004; Cabrera et al. 2009; Jung et al. 2009; Illa et al. 2011; Klagges et al. 2013), peach can serve as a model genome for the genus. In the present study, we identified the peach $C N R$ gene family and investigated the possibility that two members are candidates for the control of two fruit size QTL in cherry.

\section{Materials and methods}

Identification of $C N R$ gene family members in the peach genome

The protein sequences of tomato FW2.2 (Frary et al. 2000) and maize CNRs (Guo et al. 2010) were retrieved from NCBI (http://www.ncbi.nlm.nih.gov/). To identify the $C N R$ family members in the peach genome sequence v1.0 (International Peach Genome Initiative; http://www.rosaceae.org/peach/genome), the algorithm BLASTP was used. The genes were named PpCNR ( $P$. persica Cell Number Regulator) followed by a number, based on their order on the peach genome scaffolds. Their predicted protein sequences were retrieved and aligned to known FW2.2/CNR proteins using the set of animal, fungi and plant sequences analyzed by Guo et al. (2010). Additional tomato $F W 2.2 / C N R$ genes were identified from SGN (http://solgenomics.net/), resulting in 19 tomato members presumably representing the entire family. Also included were other recently published CNR-like genes, viz. avocado Pafw2.2-like (Dahan et al. 2010), soybean GmFWL1 (Libault et al. 2010) and tobacco NtMCA1 and NtMCA2 (Kurusu et al. 2012). Sequence alignment and phylogenetic analyses were conducted using MEGA version 5 (Tamura et al. 2011). The protein sequences were aligned by $\mathrm{Clu}-$ stalW using the BLOSUM protein weight matrix and gap opening and extension penalties of 10 and 0.1 , respectively. A neighbor-joining tree was then built using the Poisson substitution model and uniform rates, and statistical support was obtained by bootstrap analysis with 1,000 replicates.

\section{Plant materials}

The first of two sweet cherry segregating F1 populations used in this study, $\mathrm{N} \times \mathrm{E}$, consisted of 557 individuals derived from reciprocal crosses between the large-fruited landrace cultivar Emperor Francis (E) and the small-fruited, wild mazzard genotype New York $54(\mathrm{~N})$, and is maintained at the Michigan State University's Clarksville Research Center in Clarksville, MI, USA. The second F1 population, $\mathrm{R} \times \mathrm{L}$, consisted of 133 individuals obtained from the cross between the cultivars Regina (R) and Lapins (L), and grown at the Institute National de la Recherche Agronomique in Bordeaux, France. Subsets of both of these populations have been previously used for genetic linkage map construction and the mapping of fruit weight QTL (N × E: Olmstead et al. 2008; Zhang et al. 2010; $\mathrm{R} \times$ L: Dirlewanger et al. 2004; 2009). In addition, a set of 17 sweet cherry cultivars, previously determined to reflect the range of diversity in sweet cherry germplasm (Cabrera et al. 2012), was used to assess allelic variation of the $C N R$ candidate genes identified. Four of the 17 selections were the parents of the two sweet cherry F1 populations used in this study.

In sour cherry, five bi-parental F1 populations were evaluated. The largest population, M172 × 25-02-29, consisted of 79 individuals, followed by Újfehértói Fürtös $\times$ Surefire $(n=72) ; \quad 25-14-20 \times 25-02-29$ $(n=57)$; Montmorency $\times 25-02-29(n=36)$; and Rheinische Schattenmorelle (RS) $\times$ Englaise Timpurii (ET) $(n=22)$, totaling 274 individuals including parents. All sour cherry individuals are maintained at the Michigan State University's Clarksville Research Center in Clarksville, MI, USA. 
Trait measurements

Phenotypic data for the sweet cherry $\mathrm{N} \times \mathrm{E}$ and $\mathrm{R} \times \mathrm{L}$ populations were collected for 3 years (2009-2011 and 2008-2010, respectively). For the $\mathrm{N} \times \mathrm{E}$ population, in 2009 , phenotyping was performed on all the fruiting plants $(n=436)$, while in 2010 and 2011 phenotyping was conducted on those $\mathrm{N} \times$ E progeny individuals that carried a recombination breakpoint in the fruit weight QTL interval on G2 to enable more precise mapping of the fruit weight QTL. Fruit weight of the $\mathrm{N} \times$ E progeny individuals was measured by weighing five individual fruit that were collected twice and the mean weight was calculated for both collections. For the $\mathrm{N} \times \mathrm{E}$ population, mesocarp cell number data that was previously collected in 2006 and 2008 and used to identify the cell number QTL on cherry G2 overlapping with the fruit size QTL (Zhang et al. 2010) was also used. To calculate flesh weight in the $\mathrm{N} \times \mathrm{E}$ progeny, fruit weight and pit weight were recorded for each fruit in 2011. Flesh weight was calculated by subtracting pit weight from total fruit weight for each fruit. For the $\mathrm{R} \times \mathrm{L}$ progeny, the mean weight of 50 fruit was measured for all the individuals that could be harvested ( $n=104, n=116$ and $n=114$ in 2008, 2009 and 2010, respectively). For sour cherry, fruit and pit weights were measured for each of five individual fruit that were collected twice and the mean weight was calculated. Mean flesh weight was calculated by subtracting the mean pit weight from the mean fruit weight for these same five fruit.

Sequencing of candidate fruit weight $C N R \mathrm{~s}$ in cherry

Taking advantage of the synteny between the peach and cherry genomes, and the presence of conserved markers on the peach and cherry genetic maps (G2: CPSCT038, BPPCT034; G6: PR86), the genomic regions of peach corresponding to the two sweet cherry fruit size QTL were identified (Zhang et al. 2010). A peach $C N R$ gene was found within each of these G2 and G6 regions, PpCNR12 and PpCNR20, respectively. Whole-genome shotgun sequences of four sweet cherry (New York 54, Emperor Francis, Attika and Napoleon, at $2.5 \times, 3.9 \times, 3.8 \times$ and $2.1 \times$ coverage, respectively), and two sour cherry (Rheinische Schattenmorelle and 23-23-13, at $2.3 \times$ and $0.7 \times$ coverage, respectively) genotypes were obtained to identify the best cherry ortholog sequences for PpCNR12 and PpCNR20. Contig fragments (300 bp on average) were built de novo with Velvet (http://genome.cshlp.org/content/18/5/821.short) with optimized parameters using a subset of 76-bp pairedend reads that correspond to the G2 and G6 fruit weight QTL regions from peach. Consensus cherry contigs corresponding to the genomic regions of $P p C N R 12$ and PpCNR20 were obtained and used for primer development. Six primer pairs (CNR12-C1 to CNR12-C6 and CNR20-C1 to CNR20-C6, Supplementary Table S1) designed to amplify fragments of approximately $700-1,100 \mathrm{bp}$, and tailed with the M13F and M13R sequences to facilitate highthroughput sequencing, were used to sequence each gene region.

PCR reactions were conducted using the following parameters: $1 \times$ PCR buffer, $0.2 \mathrm{mM}$ each $\mathrm{dNTP}$, $1.5 \mathrm{mM} \mathrm{MgCl} 2,0.5 \mu \mathrm{M}$ each primer, $2 \mathrm{ng} / \mu \mathrm{L}$ genomic DNA and $0.02 \mathrm{U} / \mu \mathrm{L}$ Taq DNA polymerase (Invitrogen, Carlsbad, CA, USA). Cycling conditions were as follows: initial denaturation for $3 \mathrm{~s}$ at $95{ }^{\circ} \mathrm{C}$; 30 cycles of annealing for $45 \mathrm{~s}$ at $60^{\circ} \mathrm{C}$, extension for $90 \mathrm{~s}$ at $72{ }^{\circ} \mathrm{C}$ and denaturation for $30 \mathrm{~s}$ at $95{ }^{\circ} \mathrm{C}$; and a final extension for $10 \mathrm{~s}$ at $72{ }^{\circ} \mathrm{C}$. PCR products were separated using electrophoresis and visualized on a $1.2 \%$ agarose gel, and amplicon concentration was estimated by comparison with the closest band of a 100-bp and 1-kb DNA ladder (New England Biolabs, Ipswich, MA, USA). Purification of PCR products was carried out using ExoSAP-IT (Affymetrix, Santa Clara, CA, USA) according to the manufacturer's instructions and the PCR amplicons were sequenced using M13 forward and reverse sequencing primers at the Michigan State University Research Technology Support Facility. Sequencher 5.0 (Gene Codes Corporation, Ann Arbor, MI, USA) was used to align the reads and call double peaks corresponding to heterozygous SNP positions. The two cherry genes were named PavCNR (for P. avium CNR) 12 and 20.

Analysis of PavCNR12 and PavCNR20 allelic variation in sweet cherry

The sequences for the PavCNR12 alleles and upstream regions were deduced by sequencing the parents, the representatives of the homozygous individuals from the $\mathrm{N} \times \mathrm{E}$ and $\mathrm{R} \times \mathrm{L}$ progenies, and the 17 diverse 
sweet cherry cultivars to determine the sequence of each haplotype. Sequences were aligned to the peach ortholog and the coding sequence was deduced accordingly. The sequences were also analyzed using TSSP (Solovyev and Shahmuradov 2003) to predict the transcript start site. Subsequently, the PavCNR12 alleles were distinguished by the sequences of fragment CNR12-C2, which contained six polymorphic sites differentiating the three alleles. Sequencing of the $\mathrm{C} 2$ fragment was carried out for all of the progeny individuals showing recombination or ambiguities in the region between CPSCT038 and BPPCT034 (Cabrera 2011), plus a number of non-recombinant individuals representing all the G2 QTL genotypic classes.

Sequencing of PavCNR2O alleles was performed with DNA from New York 54, Emperor Francis, Ambrunes and Cristobalina using primers tailed with the M13F and M13R sequences (Supplementary Table S1). However, attempts to obtain the full-length sequence for $\operatorname{PavCNR2O}$ failed due to the presence of insertion/deletion polymorphisms hampering the read of chromatograms obtained from amplification of heterozygous genotypes. Consequently, the sequence information obtained covered only a non-contiguous portion of the gene. Interestingly, one of the primer pairs (CNR20-C1, Supplementary Table S1) only amplified a fragment from New York 54, highlighting the presence of a unique allele in this genotype; this primer pair was then used to assay the presence of the same allele in the remaining set of 13 sweet cherry cultivars.

Fine mapping of the PavCNR12 region in sweet cherry

A total of nine simple sequence repeat (SSR) primer pairs were developed in silico from the peach genomic region syntenic to the sweet cherry G2 fruit weight QTL region previously described (Zhang et al. 2010) (G2SSR1576, G2SSR1580, G2SSR1610, G2SSR1672, G2SSR1678, G2SSR1675, G2SSR1818, G2SSR1823, G2SSR1864; Supplementary Table S2). The SSRs were identified from regions close to predicted genes using SSRIT (Temnykh et al. 2001) and WebSat (Martins et al. 2009). Flanking primers were developed using Primer3 v0.4.0 (Rozen and Skaletsky 2000; http://frodo.wi.mit.edu/primer3) and a M13 tail (CACGACGTTGTAAAACGAC) was added to the $5^{\prime}$ end of all of the forward primers to facilitate labeling of products during the PCR reaction. In addition, a primer pair for one SNP marker (G2SNP1623, Supplementary Table S2) identified after sequencing a peach intergenic region was designed for genotyping using the allele-specific primer extension (ASPE) method using the Luminex technology (Luminex, Corp., Austin, TX, USA). A polymerase-mediated primer extension identified the base at a specific SNP on a previously amplified product (Supplementary Table S2). Uniquely colored microspheres were attached to specific products and the fluorescence of a reporter molecule (streptavidin) was quantified by a laser in a Luminex 200 analyzer (Lee et al. 2004).

SSRs were run on a $6.5 \%$ LI-COR $\mathrm{KB}^{\text {Plus }}$ gel (LI-COR, Lincoln, NE, USA). The reaction mixture for the SSR amplification contained $1 \times$ PCR buffer, $2 \mathrm{mM} \mathrm{MgCl}_{2}, 100 \mu \mathrm{M}$ of each dNTP, $0.02 \mu \mathrm{M}$ of each primer, $1 \mu \mathrm{M}$ LI-COR primer (IRDye700 or IRDye800) and $0.3 \mathrm{U} / \mu \mathrm{L}$ Taq DNA polymerase. Conditions for PCR amplification were as follows: initial denaturation at $94{ }^{\circ} \mathrm{C}$ for $1 \mathrm{~min}$; 31 cycles of $92{ }^{\circ} \mathrm{C}$ for $40 \mathrm{~s}, 56^{\circ} \mathrm{C}$ for $45 \mathrm{~s}$ and $72{ }^{\circ} \mathrm{C}$ for $2 \mathrm{~min}$, and a final extension at $72{ }^{\circ} \mathrm{C}$ for $4 \mathrm{~min}$. Fragments were detected by excitation of fluorescence added during the PCR reaction with either IRDye700 or IRDye800 primers following the M13-tailed PCR protocol (Schuelke 2000). A total of 549 individuals from the $\mathrm{N} \times \mathrm{E}$ population and 133 individuals from the $\mathrm{R} \times \mathrm{L}$ population were genotyped with these new markers at the Molecular and Cellular Imaging Center in Wooster, $\mathrm{OH}$, USA. Map distances for markers in the G2 QTL region were calculated using JoinMap 3.0 (Van Ooijen and Voorrips 2002).

Genotyping markers linked to PcrCNR12 and $P$ crCNR2O in sour cherry

Orthologs of PavCNR12 and PavCNR20, named PcrCNR (for P. cerasus CNR) 12 and 20, were amplified from sour cherry using the same primer sets used for sweet cherry (Supplementary Table S1). However, sequence alignments of amplicons from sour cherry were not possible due to the tetraploid and highly heterozygous nature of the genomic regions. Instead, the peach genome was utilized to identify SSRs in transcripts near the genes $P p C N R 12$ and $P p C N R 20$. Primer3 was used for primer design. PCR fragments for the G2and G6-associated SSRs (G2SSR1566 and G6SSR2208, respectively; Supplementary Table S2) 
were amplified, separated on $5 \%$ polyacrylamide gels and visualized with silver staining. When the SSR fragments sizes for sour cherry were equivalent to those for sweet cherry, flanking SNP genotypes previously obtained using the Cherry $6 \mathrm{~K}$ Infinium ${ }^{\circledR}$ II array (Peace et al. 2012) were used to determine allele identity.

\section{Statistical analysis}

To test the likelihood of PavCNR12 as the underlying candidate gene for the G2 QTL, an analysis of variance (ANOVA) implemented in $\mathrm{R}$ stat version 2.15.1 (R Development Core Team, 2012) was conducted. ANOVA was performed using the following general linear model, in which both the allele main effects and interactions were tested for significance:

$\boldsymbol{Y}=\boldsymbol{X} \boldsymbol{\beta}+\boldsymbol{\varepsilon}$

where $\boldsymbol{Y}$ is a vector $(n \times 1)$ of observed phenotypic values for $n$ individuals, $\boldsymbol{X}$ is a customized design matrix with $n \times p$ fixed constants for all allele main effects and multi-way interactions, and $p$ is the number of $x$ parameters (both fixed main and interaction effects). The alleles were assumed to be additive. Therefore, for the diploid (sweet cherry) case, 0,1 and 2 were assigned for absence, single and two dosages of a particular allele, respectively. For the tetraploid (sour cherry) case $0,1,2,3$ and 4 were assigned for absence, single, two, three and four dosages of particular alleles, respectively. Both main-effect and higher level interactions were considered. $\boldsymbol{\beta}$ is a $n \times 1$ unknown fixed effects parameter vector. $\boldsymbol{\varepsilon}$ is a $n \times 1$ vector of residuals (random errors). Kruskal-Wallis tests were also conducted, resulting in similar results to the ANOVA. $P$ values $<0.05$ were reported as significant. Data for 3 years from each sweet cherry population were initially analyzed separately; then, to combine data from different years, values within each year were standardized using the following formula:

$x_{\text {std }}=\frac{(x-\bar{x})}{\sigma}$

where $\bar{x}$ and $\sigma$ are the mean and standard deviation of the data in that year; the mean of standardized values was then calculated for each genotype, obtaining a single dataset for each trait.

The mean trait comparisons among genotypic classes for PavCNR12 and PavCNR2O in sweet cherry were done using the Newman-Keuls test implemented in SAS version 9.0 (SAS Institute, Cary, NC, USA). In the case of tetraploid sour cherry, a two-tailed Student's $t$ test was used to compare the trait means of two classes, e.g. individuals with the putative allele versus individuals without the putative allele for the SSR marker loci closely linked to both $C N R$ candidate genes.

The threshold for significance was set at $P<0.05$.

\section{Results}

Identification of the peach $C N R$ gene family members and candidate genes for cherry fruit size QTL

A total of $23 C N R$ gene family members were identified in the peach genome, with at least one $C N R$ gene identified on each of the eight chromosomes (Supplementary Table S3 and Fig. 1). The structure for most of the peach $C N R$ genes consisted of two or three introns; however, one gene had four introns (PpCNR17), two genes had six introns ( $P p C N R 13$ and $22)$, and one gene was intronless (PpCNR14) (Supplementary Fig. S1). The deduced protein sequences ranged from 84 to 445 residues, with the majority of the CNRs (16 out of 23) consisting of between 100 and 255 amino acids. While each of the eight peach chromosomes contained $C N R$ family members, chromosome 1 had the most, $11 C N R \mathrm{~s}$. Eight of the $C N R \mathrm{~s}$ on chromosome 1 (PpCNRO1 to 08) formed a dense cluster between 3.056 and $3.139 \mathrm{~kb}$ (Supplementary Table S3 and Fig. 1). The phylogenetic analysis carried out on these deduced protein sequences (Fig. 2) indicated homology between these eight genes, suggesting that they likely originated from a series of recent tandem duplication events.

The deduced peptide sequences of the 23 PpCNRs had amino acid identities with the closest FW2.2/ maize CNRs ranging from 21.0 to $65.6 \%$. The composition of the PpCNRs tended to be rich in cysteine and proline, with an average of $7.40 \%$ for both amino acids. Three proteins (PpCNR9, 15 and 18) contained the CLXXXXCPC conserved motif found in the cluster of cell-number regulating proteins containing FW2.2 and ZmCNR1. Three other proteins (PpCNR10, 11 and 21) contained the motif CCXXXXCPC, reported for ZmCNR2 and some cadmium resistance-related proteins. Finally, in three 
Fig. 1 Position of the 23 CNR homologs identified in the eight peach genome scaffolds

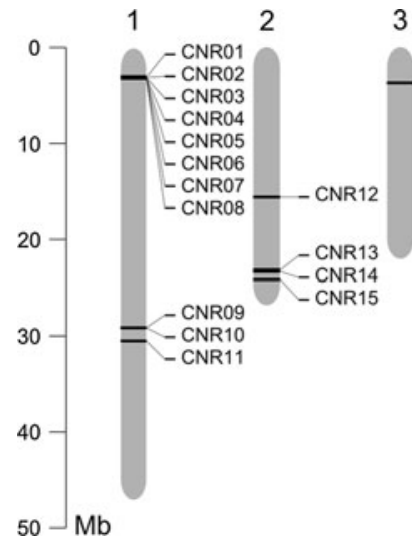

other peptides (PpCNR12, 17 and 23) this motif is partially conserved as CXXXXXCPC. The peach homolog most similar to tomato FW2.2 and maize ZmCRN1 was PpCNR23 (Fig. 2).

To investigate whether peach $C N R$ genes were located within the sweet cherry fruit size QTL regions, the sequence between the two SSR markers that flank the G2 fruit weight QTL, CPSCT038 (at $15.057 \mathrm{Mb}$ ) and BPPCT034 (at $16.491 \mathrm{Mb}$ ), was examined. $P p C N R 12$ (identified in the peach genome as transcript ppa026136 m) was identified on scaffold 2 at approximately $15.650 \mathrm{Mb}$ (Supplementary Table S3) and therefore qualified as a likely candidate gene for the G2 fruit size QTL (Fig. 3a). The G6 fruit weight QTL was near marker PR86 (Zhang et al. 2010), which is located approximately $1 \mathrm{Mb}$ from PpCNR20 (ppa008853 m) (Supplementary Table S3, Fig. 3a). Therefore, $P p C N R 20$ is a likely candidate gene for the G6 fruit size QTL.

\section{Identification of $P a v C N R 12$ allelic variants}

The consensus sequence of PavCNR12 consisted of $4,375 \mathrm{~kb}$, including $1,491 \mathrm{bp}$ upstream of the start codon and $117 \mathrm{bp}$ downstream of the stop codon. The coding region, which is 768 bp long, was interrupted by three introns of 341,517 and 1,141 bp. The deduced protein sequence of PavCNR12 has 255 residues with an amino acid identity of $97.6 \%$ with its peach ortholog PpCNR12 and $66.8 \%$ with maize ZmCNR6. The percentages of cysteine and proline residues are $6.67 \%$ and $7.45 \%$, respectively, and the protein is predicted to harbor the CXXXXXCPC motif.

To determine the allelic variation for PavCNR12, the gene and upstream region were sequenced from 17 sweet cherry cultivars chosen to represent a diverse array of sweet cherry germplasm (Cabrera et al. 2012, Supplementary Table S4). The sequenced PavCNR12 fragments revealed no polymorphisms within the coding regions and 14 nucleotide polymorphisms in the non-coding regions that collectively distinguished three unique PavCNR12 sweet cherry alleles (Fig. 3b, Supplementary Figure S2). Of these, 10 polymorphisms resided in the $5^{\prime}$ region upstream of the start codon, one in the second intron and three in the third intron (Fig. 3b). Seven out of 17 sequenced cultivars were homozygous for the most prevalent allele, named PavCNR12-1 (Supplementary Table S4). A second allele, PavCNR12-2, was identified in both Regina and Lapins and its haplotype was confirmed by sequencing $\mathrm{R} \times \mathrm{L}$ progeny individuals homozygous for this second allele (Supplementary Table S4). The same two alleles identified in Regina and Lapins were also present in Emperor Francis. Finally, a third allele (PavCNR12-3) was identified in New York 54. The sequencing of the PavCNR12 haplotypes in the 17 founder lines allowed us to determine the allelic composition in 16 sweet cherry cultivars. The only unique haplotype was found for Cristobalina, which showed a SNP in the third intron of the otherwise PavCNR12-3 haplotype (Supplementary Figure S2). Therefore, we considered Cristobalina to carry the PavCNR12 1/3 alleles (Supplementary Table S4).

As most of the polymorphic sites were located in the region between 1,100 and 300 bp upstream of the start codon, the sequences of the three alleles were analyzed by TSSP to predict promoter and enhancer elements. For PavCNR12-1 the putative transcription start site (TSS) was placed at position 1,077 $(-415$ from the start codon), with a TATA box at 1,044 (-448). For 


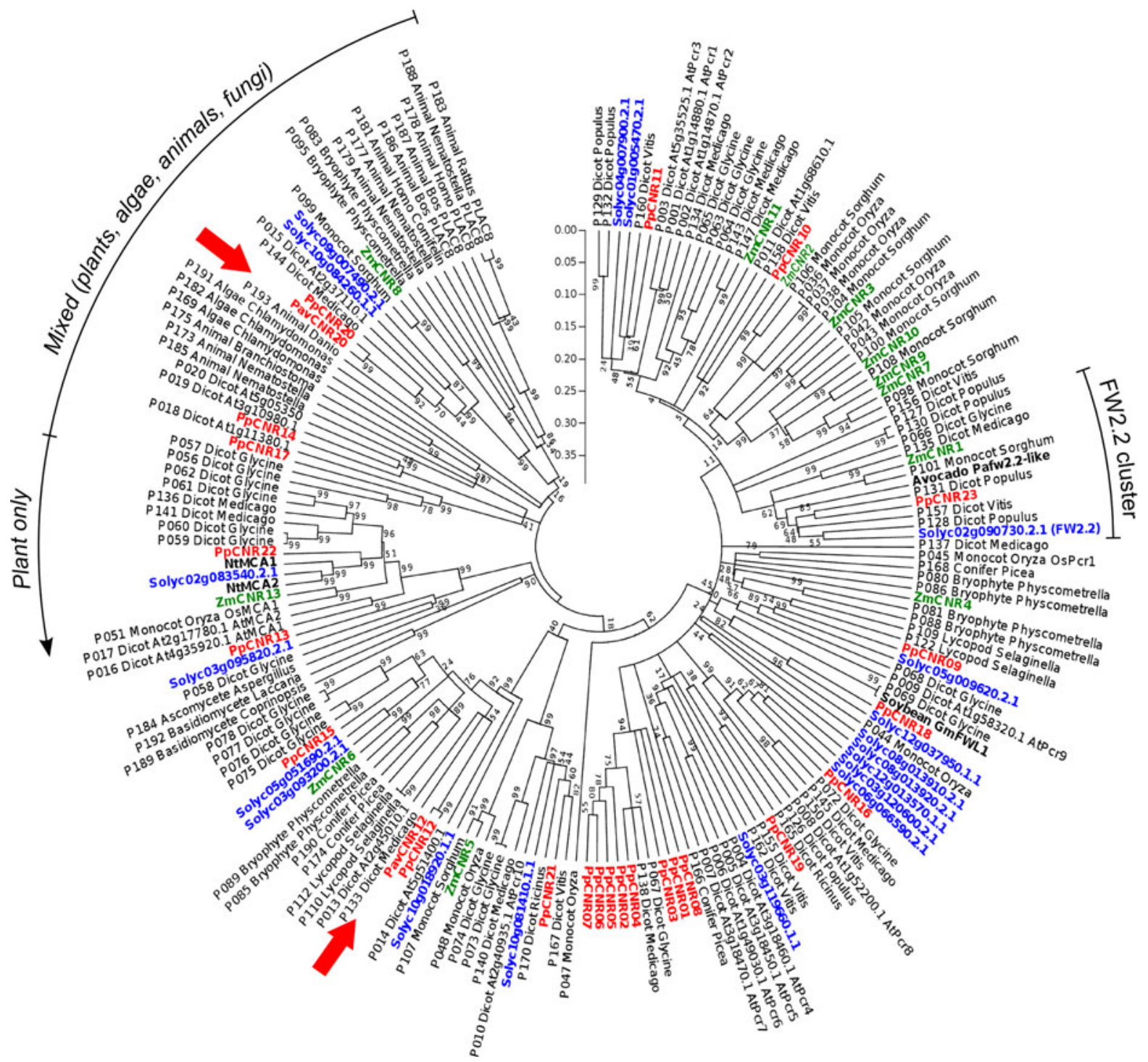

Fig. 2 Neighbor-joining tree of $F W 2.2 / C N R$ homologs from diverse taxa (derived from Guo et al. 2010). The tree includes the entire families identified in maize (green), tomato (blue) and

PavCNR12-2 and PavCNR12-3, the TSS was placed closer to the start codon, at position $1,174(-318)$, with the TATA box at 1,151 (-341). The sequences of PavCNR12-1, PavCNR12-2 and PavCNR12-3 were submitted to Genbank (accession numbers KC139086, KC139087 and KC139088, respectively).

Identification of $\operatorname{PavCNR} 20$ allelic variants

In sweet cherry, the fragments from Emperor Francis, Ambrunes and Cristobalina resulting in readable
Prunus (red); the two candidates for the control of fruit size in cherry (PavCNR12 and PavCNR2O) are indicated by red arrows. (Color figure online)

sequences were from CNR20-C4 through C6. This yielded a contig of approximately $1.8 \mathrm{~kb}$, corresponding to the $3^{\prime}$ portion of the gene and encoding 141 C-terminal amino acids. No polymorphisms were found in this region between the three cultivars and the sequence was submitted to Genbank (accession number KC154001). C1 primer pairs did not amplify a product, and $\mathrm{C} 2$ and $\mathrm{C} 3$ resulted in double peaks indicative of several indels close to the primer sites in these three cultivars. From New York 54, only fragment CNR20-C1 could be amplified and 
Fig. 3 a Position of fruit weight (FW) QTL in sweet cherry G2 and G6 (from Zhang et al. 2010) and identification of the corresponding regions in peach scaffolds; two $C N R$ genes whose position is compatible with the QTL region are indicated by arrows. b Polymorphisms differentiating the three PavCNR12 alleles. The coding sequence is represented in thick dark grey bars, and introns in light gray

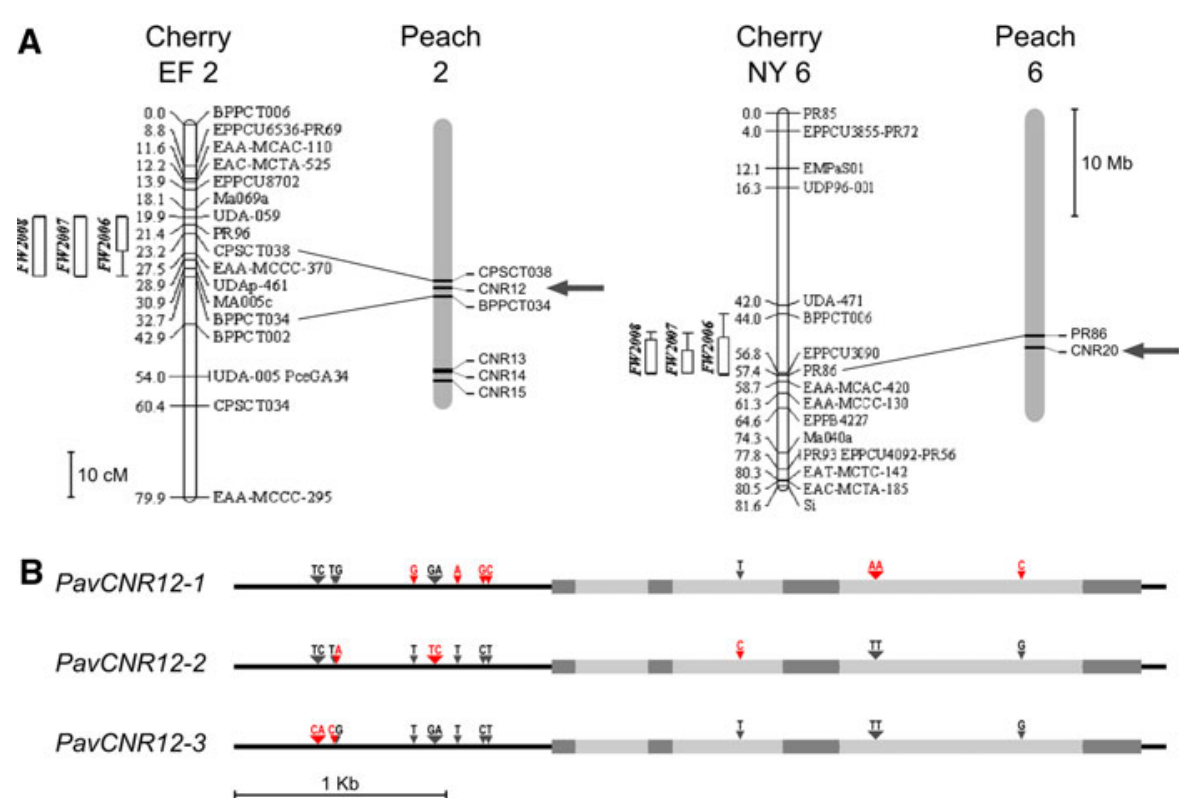

sequenced. All other fragments from the wild mazzard resulted in unreadable chromatograms. In both New York 54 and the cultivars, the CNR2O alleles either were divergent or primer pairs amplified two closely related paralogs rather than a single gene. Nevertheless, it appeared that the two New York 54 alleles for CNR20 are more diverse than those in the cultivars.

Since the G6 sweet cherry fruit weight QTL was only segregating in the New York 54 parent (Zhang et al. 2010), we sought to determine whether any of the sweet cherry founder lines carried the small fruit allele from the wild mazzard. The primer pair CNR20-C1 was used to test the presence of this allele and showed that none of the 16 sweet cherry cultivars resulted in amplification of this fragment, suggesting that the small fruit allele is unique to New York 54.

Association of PavCNR12 allelic variants with phenotypic variation

The PavCNR12 genotypes of New York (1/3) and Emperor Francis (1/2), were consistent with those predicted from the previous QTL analysis where both parents were shown to share one common G2 QTL haplotype while each possessing a second unique QTL haplotype (Zhang et al. 2010). The heterozygous PavCNR12 genotypes found for Lapins (1/2) and Regina (1/2), were also consistent with the previous finding that both parents were heterozygous for the G2 fruit size QTL (Dirlewanger et al. 2009).

To determine whether the three PavCNR12 alleles were associated with fruit size variation in sweet cherry, the segregation was first analyzed in the two sweet cherry $\mathrm{F} 1$ populations. In $\mathrm{N} \times \mathrm{E}$, the four genotypic classes for PavCNR12 were (1/1):(1/2):(1/3):(2/3) and segregated in the ratio 125:136:115:170, while in $\mathrm{R} \times \mathrm{L}$ the ratio between the three classes $(1 / 1):(1 / 2):(2 / 2)$ was 23:61:37. The genotypic frequencies did not differ significantly $\left(P>0.05 ; \chi^{2}\right.$ test $)$ from the expected ratios of 1:1:1:1 and 1:2:1, respectively. In $N \times E$, mean fruit weights were significantly different $(P<0.05)$ depending on the $P a v C N R 12$ genotype present in progeny individuals (Table 1). Progeny individuals with the genotypes $P a v C N R 12-1 / 1$ and -2/3 consistently showed the highest and the lowest fruit weight means, respectively. However the fruit weight difference between PavCNR12-1/1 progeny individuals and the second largest class ( $P a v C N R 12-1 / 2$ progeny individuals) was significant only in one out of 3 years (2011), while $P a v C N R 12-2 / 3$ progeny individuals had significantly smaller mean fruit weights than any other genotypic group in 2009 and 2010. Of the remaining genotypes, progeny with $P a v C N R 12-1 / 2$ had a slightly higher mean fruit weight than $P a v C N R 12-1 / 3$ progeny individuals, and in 1 year (2009) the difference between the two groups was significant. 
Table 1 Phenotypic means for PavCNR12 genotypic classes of progeny individuals from the populations New York $54 \times$ Emperor Francis $(\mathrm{N} \times \mathrm{E})$ and Regina $\times$ Lapins $(\mathrm{R} \times \mathrm{L})$

\begin{tabular}{|c|c|c|c|c|c|c|c|}
\hline \multirow[t]{2}{*}{ Population } & \multirow[t]{2}{*}{ Trait means } & \multirow[t]{2}{*}{ Years } & & \multicolumn{4}{|c|}{ PavCNR12 genotype } \\
\hline & & & & $1 / 1$ & $1 / 2$ & $1 / 3$ & $2 / 3$ \\
\hline \multirow[t]{15}{*}{$\mathrm{N} \times \mathrm{E}$} & \multirow[t]{6}{*}{ Fruit wt (g) } & \multirow[t]{2}{*}{2009} & $N^{\mathrm{a}}$ & 102 & 106 & 86 & 142 \\
\hline & & & Mean $^{\mathrm{b}}$ & $4.48^{\mathrm{A}}$ & $4.41^{\mathrm{A}}$ & $4.09^{\mathrm{B}}$ & $3.69^{\mathrm{C}}$ \\
\hline & & \multirow[t]{2}{*}{2010} & $N$ & 32 & 19 & 19 & 37 \\
\hline & & & Mean & $4.76^{\mathrm{A}}$ & $4.42^{\mathrm{A}, \mathrm{B}}$ & $4.28^{\mathrm{B}}$ & $3.85^{\mathrm{C}}$ \\
\hline & & \multirow[t]{2}{*}{2011} & $N$ & 44 & 40 & 43 & 52 \\
\hline & & & Mean & $3.88^{\mathrm{A}}$ & $3.65^{\mathrm{B}}$ & $3.56^{\mathrm{B}}$ & $3.41^{\mathrm{B}}$ \\
\hline & \multirow[t]{2}{*}{ Pit wt (g) } & \multirow[t]{2}{*}{2011} & $N$ & 44 & 40 & 43 & 52 \\
\hline & & & Mean & $0.283^{\mathrm{A}}$ & $0.255^{\mathrm{B}}$ & $0.264^{\mathrm{A}, \mathrm{B}}$ & $0.272^{\mathrm{A}, \mathrm{B}}$ \\
\hline & \multirow[t]{2}{*}{ Flesh wt (g) } & \multirow[t]{2}{*}{2011} & $N$ & 44 & 40 & 43 & 52 \\
\hline & & & Mean & $3.60^{\mathrm{A}}$ & $3.39^{\mathrm{A}, \mathrm{B}}$ & $3.30^{\mathrm{B}, \mathrm{C}}$ & $3.13^{\mathrm{C}}$ \\
\hline & \multirow[t]{4}{*}{ Mesocarp cell number ${ }^{\mathrm{c}}$} & \multirow[t]{2}{*}{2006} & $N$ & 18 & 35 & 23 & 46 \\
\hline & & & Mean & $38.0^{\mathrm{A}}$ & $32.1^{\mathrm{B}}$ & $31.9^{\mathrm{B}}$ & $30.7^{\mathrm{B}}$ \\
\hline & & \multirow[t]{2}{*}{2007} & $N$ & 19 & 41 & 26 & 48 \\
\hline & & & Mean & $37.6^{\mathrm{A}}$ & $32.7^{\mathrm{B}}$ & $32.2^{\mathrm{B}}$ & $31.0^{\mathrm{B}}$ \\
\hline & & & & \multicolumn{2}{|r|}{$1 / 1$} & $1 / 2$ & $2 / 2$ \\
\hline \multirow[t]{6}{*}{$\mathrm{R} \times \mathrm{L}$} & \multirow[t]{6}{*}{ Fruit wt (g) } & \multirow[t]{2}{*}{2008} & $N$ & \multicolumn{2}{|r|}{19} & 53 & 32 \\
\hline & & & Mean & \multicolumn{2}{|r|}{$9.34^{\mathrm{A}}$} & $8.22^{\mathrm{B}}$ & $6.52^{\mathrm{C}}$ \\
\hline & & \multirow[t]{2}{*}{2009} & $N$ & \multicolumn{2}{|r|}{23} & 58 & 35 \\
\hline & & & Mean & \multicolumn{2}{|r|}{$8.67^{\mathrm{A}}$} & $7.83^{\mathrm{B}}$ & $6.25^{\mathrm{C}}$ \\
\hline & & \multirow[t]{2}{*}{2010} & $N$ & \multicolumn{2}{|r|}{22} & 58 & 34 \\
\hline & & & Mean & \multicolumn{2}{|r|}{$8.29^{\mathrm{A}}$} & $7.47^{\mathrm{B}}$ & $6.28^{C}$ \\
\hline
\end{tabular}

${ }^{a}$ Number of individuals

b Values marked with the same letter within a row are not significantly different (ANOVA, $P>0.05$ )

c Mesocarp cell number data is from Zhang et al. (2010)

Total fruit weight is the result of the combined weight of the pit and flesh. To determine whether the G2 fruit weight QTL is predominantly associated with flesh weight, the three PavCNR12 alleles were evaluated for their association with flesh and pit weight (Table 1). Progeny individuals with the PavCNR12-1/1 genotype showed the highest mean fruit weight and also the highest mean flesh weight. Progeny individuals with the PavCNR12-2/3 genotype exhibited the lowest mean fruit weight and the lowest mean flesh weight. This suggested that the QTL effect on fruit size was mainly due to differences in the flesh rather than pit size.

The co-localization on G2 of a QTL for mesocarp cell number with the QTL for fruit size led to the presumption that differences in cell number might contribute to the differences in fruit size (Zhang et al. 2010). In the present study, mean mesocarp cell numbers were compared among the four PavCNR12 progeny classes segregating in the $\mathrm{N} \times$ E population (Table 1). Progeny with the PavCNR12-1/1 genotype had a mean mesocarp cell number significantly higher than any other genotypic group in both years (38.0 and 37.6).

The $\mathrm{R} \times \mathrm{L}$ progeny population showed the mean fruit weight for the homozygous and heterozygous classes for the PavCNR12 alleles 1 and 2 (Table 1). The mean values between the three genotypic classes were consistently significantly different $(P<0.05)$ from each other in all 3 years. Most notably, progeny with the homozygous genotype PavCNR12-1/1 had the highest mean fruit weight, similar to that observed in $\mathrm{N} \times \mathrm{E}$, while progeny with the homozygous genotype PavCNR12-2/2 had the smallest mean fruit weight. 
To test the likelihood of PavCNR12 being the underlying gene responsible for the G2 fruit size QTL, additional G2 markers were developed between markers CPSCT038 and BPPCT034 and extending to the previously reported SSR MA007a (Olmstead et al. 2008). These marker scores, including PavCNR12, were analyzed along with fruit size data in a linear model ANOVA with additive effects and resulting probability values were scaled as $-\log _{10}(P)$. The majority of markers in the region containing $P a v C N R 12$ were significantly associated $[P<0.01$ or $\left.-\log _{10}(P)>2\right]$ with fruit size variation (Supplementary Fig. S3). In $\mathrm{N} \times \mathrm{E}$, the most probable location of the fruit weight QTL standardized across 3 years was placed on marker G2SSR1576, immediately downstream of PavCNR12. This is also the most probable location of the flesh weight QTL. By comparison, the peak for mesocarp cell number was placed on RosCOS1634, which was located immediately upstream of PavCNR12 (Supplementary Fig. S3). Interestingly, the analysis highlighted a second peak around marker BPPCT034 in the $\mathrm{N} \times \mathrm{E}$ population. While in most years this was a minor peak, in 2009 marker BPPCT034 showed the most significant association with fruit weight, suggesting a second fruit weight QTL in the $\mathrm{N} \times \mathrm{E}$ population. The strong association of fruit size variation over the region may be due to the small number of recombinant individuals for the region and the high effect of the underlying gene on fruit weight. The $-\log _{10}(P)$ values for 2010 and 2011 were lower than those in 2009. This is because in 2010 and 2011 fewer individuals were evaluated, since only recombinant individuals and controls were studied for fruit size. The same analysis was carried out for the $\mathrm{R} \times \mathrm{L}$ progeny population (Supplementary Fig. S3). In this population, only one fruit weight QTL was found and the PavCNR12 allele consistently corresponded to the most significant marker for mean fruit weight across all the 3 years of analysis (Table 1).

\section{Analysis of markers near PcrCNR12 and $\operatorname{PcrCNR} 20$ in sour cherry}

For sour cherry, due to the difficulty in obtaining quality sequence data of amplicons derived from the PcrCNR12 and PcrCNR2O loci, two SSR markers were developed that are in close proximity to $P p C N R 12$ and PpCNR20. Based on the peach genome sequence, the first SSR developed was $18 \mathrm{~kb}$ downstream of PpCNR12 (marker G2SSR1566) and the second SSR developed was $13 \mathrm{~kb}$ downstream of PpCNR20 (G6SSR2208) (Supplementary Table S2). Due to the proximity to the $C N R$ loci, these markers were used as proxies for the actual $C N R$ alleles.

Fragment size differences for G2SSR1566 identified a total of three and seven SSR alleles in sweet and sour cherry, respectively (Supplementary Table S5). We inferred that the 250-bp fragment identified in both sweet and sour cherry was similar based on identical flanking SSR and SNP markers (Supplementary Table S6). This 250-bp fragment was associated with the sweet cherry PavCNR12 allele 2, suggesting that this allele may also be present in sour cherry. SSR fragment sizes of 225 and 228 that were associated with alleles PavCNR12-1 and PavCNR12-3, respectively, were not identified in sour cherry, suggesting that these alleles were not in the sour cherry germplasm evaluated. Fragment size differences for G6SSR2208 identified a total of four and five SSR alleles in sweet and sour cherry, respectively (Supplementary Table S5). Based on common SSR fragment sizes and surrounding SNP markers, two of the sour cherry SSR alleles (alleles 3 and 5) may be equivalent to those in sweet cherry (Supplementary Table S6).

Association of the G2SSR1566 and G6SSR2208 alleles with fruit size in sour cherry

In sour cherry, mean fruit, pit and flesh weights were compared among individuals based upon the presence or absence of the seven G2SSR1566 alleles (Table 2). In the progeny, the presence or absence of allele 2 did not result in significant differences for any of the three phenotypic traits scored. However, significant phenotypic differences were associated with the alleles 4, 6, and most notably with allele 8 . Allele 8 on its own had a highly significant effect on fruit, pit and flesh weight, where its absence was associated with an average increase in weight (Table 2). The largest mean differences for fruit and flesh weight were identified in those individuals with or without both alleles 7 and 8 (last column in Table 2). Progeny individuals that inherited both alleles displayed a mean fruit weight of $4.66 \mathrm{~g}$ and a mean flesh weight of $4.34 \mathrm{~g}$, whereas those without the alleles had a mean fruit weight of $5.74 \mathrm{~g}$ and a mean flesh weight of $5.04 \mathrm{~g}$. This 
Table 2 Phenotypic means for the presence or absence of the G2SSR1566 alleles (linked to PcrCNR12) and G6SSR2208 alleles (linked to PcrCNR20) summed over 274 sour cherry progeny individuals

\begin{tabular}{|c|c|c|c|c|c|c|c|c|c|}
\hline & \multicolumn{3}{|c|}{ Fruit weight (g) } & \multicolumn{3}{|c|}{ Pit weight (g) } & \multicolumn{3}{|c|}{ Flesh weight (g) } \\
\hline & $N^{\mathrm{a}}$ & Mean $^{\text {b }}$ & $P$ value & $N^{\mathrm{a}}$ & Mean $^{\text {b }}$ & $P$ value & $N^{\mathrm{a}}$ & Mean $^{\text {b }}$ & $P$ value \\
\hline \multicolumn{10}{|c|}{ G2SSR1566 alleles } \\
\hline $2 /$ no 2 & $128 / 146$ & $5.64^{\mathrm{A}} / 5.30^{\mathrm{A}}$ & 0.07 & $128 / 146$ & $0.34^{\mathrm{A}} / 0.34^{\mathrm{A}}$ & 0.72 & $128 / 146$ & $5.30^{\mathrm{A}} / 4.96^{\mathrm{A}}$ & 0.06 \\
\hline 4/no 4 & $241 / 33$ & $5.41^{\mathrm{A}} / 5.85^{\mathrm{B}}$ & 0.05 & $241 / 33$ & $0.34^{\mathrm{A}} / 0.36^{\mathrm{A}}$ & 0.07 & $241 / 33$ & $5.08^{\mathrm{A}} / 5.49^{\mathrm{A}}$ & 0.06 \\
\hline $5 /$ no 5 & $33 / 241$ & $5.55^{\mathrm{A}} / 5.55^{\mathrm{A}}$ & 0.74 & $33 / 241$ & $0.32^{\mathrm{A}} / 0.34^{\mathrm{A}}$ & 0.14 & $33 / 241$ & $5.24^{\mathrm{A}} / 5.10^{\mathrm{A}}$ & 0.68 \\
\hline 6/no 6 & $116 / 158$ & $5.24^{\mathrm{A}} / 5.62^{\mathrm{B}}$ & 0.05 & $116 / 158$ & $0.34^{\mathrm{A}} / 0.34^{\mathrm{A}}$ & 0.59 & $116 / 158$ & $4.91^{\mathrm{A}} / 5.28^{\mathrm{B}}$ & 0.04 \\
\hline 7/no 7 & $122 / 152$ & $5.45^{\mathrm{A}} / 5.47^{\mathrm{A}}$ & 0.94 & $122 / 152$ & $0.35^{\mathrm{A}} / 0.33^{\mathrm{A}}$ & 0.08 & $122 / 152$ & $5.10^{\mathrm{A}} / 5.14^{\mathrm{A}}$ & 0.86 \\
\hline $8 /$ no 8 & $139 / 135$ & $5.11^{\mathrm{A}} / 5.81^{\mathrm{B}}$ & 0.0002 & $139 / 135$ & $0.33^{\mathrm{A}} / 0.35^{\mathrm{B}}$ & 0.008 & $139 / 135$ & $4.78^{\mathrm{A}} / 5.46^{\mathrm{B}}$ & 0.0002 \\
\hline 9/no 9 & $113 / 161$ & $5.57^{\mathrm{A}} / 5.38^{\mathrm{A}}$ & 0.34 & $113 / 161$ & $0.34^{\mathrm{A}} / 0.34^{\mathrm{A}}$ & 0.43 & $113 / 161$ & $5.22^{\mathrm{A}} / 5.05^{\mathrm{A}}$ & 0.34 \\
\hline $7+8 /$ no 7 or 8 & $56 / 56$ & $4.66^{\mathrm{A}} / 5.74^{\mathrm{B}}$ & 0.0004 & $56 / 56$ & $0.33^{\mathrm{A}} / 0.34^{\mathrm{A}}$ & 0.43 & $56 / 56$ & $4.34^{\mathrm{A}} / 5.40^{\mathrm{B}}$ & 0.0003 \\
\hline \multicolumn{10}{|c|}{ G6SSR2208 alleles } \\
\hline 1/no 1 & $85 / 171$ & $5.23^{\mathrm{A}} / 5.66^{\mathrm{B}}$ & 0.05 & $85 / 171$ & $0.32^{\mathrm{A}} / 0.35^{\mathrm{B}}$ & 0.03 & $85 / 171$ & $4.91^{\mathrm{A}} / 5.32^{\mathrm{A}}$ & 0.06 \\
\hline 2/no 2 & $40 / 215$ & $5.09^{\mathrm{A}} / 5.60^{\mathrm{A}}$ & 0.08 & $40 / 215$ & $0.33^{\mathrm{A}} / 0.34^{\mathrm{A}}$ & 0.25 & $40 / 215$ & $4.76^{\mathrm{A}} / 5.26^{\mathrm{A}}$ & 0.08 \\
\hline 3/no 3 & $194 / 63$ & $5.69^{\mathrm{A}} / 5.00^{\mathrm{B}}$ & 0.0005 & $194 / 63$ & $0.35^{\mathrm{A}} / 0.31^{\mathrm{B}}$ & 0.0004 & $194 / 63$ & $5.34^{\mathrm{A}} / 4.69^{\mathrm{B}}$ & 0.0006 \\
\hline 4/no 4 & $20 / 236$ & $4.19^{\mathrm{A}} / 5.64^{\mathrm{B}}$ & $<0.0001$ & $20 / 236$ & $0.29^{\mathrm{A}} / 0.35^{\mathrm{B}}$ & $<0.0001$ & $20 / 236$ & $3.89^{\mathrm{A}} / 5.29^{\mathrm{B}}$ & $<0.0001$ \\
\hline $5 /$ no 5 & $180 / 75$ & $5.52^{\mathrm{A}} / 5.55^{\mathrm{A}}$ & 0.87 & $180 / 75$ & $0.34^{\mathrm{A}} / 0.35^{\mathrm{A}}$ & 0.11 & $180 / 75$ & $5.18^{\mathrm{A}} / 5.20^{\mathrm{A}}$ & 0.94 \\
\hline
\end{tabular}

${ }^{a}$ Number of individuals

b Values marked with the same letter within a haplotype are not significantly different (ANOVA, $P>0.05$ )

represents an 18.8 and $19.6 \%$ reduction in mean flesh weight and fruit weight for those individuals that have both alleles 7 and 8 . Pit weight was not significantly associated with the simultaneous presence or absence of alleles 7 and 8 .

For the G6SSR2208 alleles, the phenotypic means showed a significant increase for fruit, pit and flesh weight with the presence of allele 3 (Table 2). When considering that this allele might be shared between sweet and sour cherry, the effect on weight was consistent with the large-fruited G6 QTL allele in both species and its effect on pit weight. On the other hand, fruit, pit, and flesh weights were significantly higher when allele 4 was absent, suggesting a large negative effect on weight by this allele.

\section{Discussion}

Cell number regulator genes and organ size

In the present study, we identified the FW2.2/CNR gene family characterized by the conserved PLAC8 domain in the genome of peach (Guo et al. 2010; Guo and Simmons 2011). Because of the role in fruit size in tomato, we sought to determine whether members of the $C N R$ family might underlie fruit weight QTL in other species. The high colinearity within the Prunus genus permitted us to evaluate whether members of the $C N R$ family in peach co-localize with important fruit weight QTL in sweet and sour cherry. We identified two CNR family members, PavCNR 12 and PavCNR20, as potential candidates to control fruit size in both sweet and sour cherry.

In plants, tomato $F W 2.2$ is the founding member of a family of genes controlling fruit size (Frary et al. 2000). FW2.2 is shown to modulate cell proliferation in the carpel ovary; thus, its effect on fruit size is exerted by regulating cell number rather than cell size. Interestingly, the coding sequences of $F W 2.2$ alleles were identical, suggesting that the differences between the large- and small-fruited allele are based on the timing and level of gene expression rather than on changes in the protein structure or functionality. This hypothesis was supported by transgenic experiments in an artificial gene dosage series (Liu et al. 2003). $F W 2.2$ acts as a negative cell number regulator, as its dosage and level of expression are negatively 
correlated with the cell division activity in the early stages of fruit development.

The control of organ size and cell number by members of the $F W 2.2 / C N R$ family could be a common regulatory mechanism in higher plants. Other members of the family Solanaceae possess overlapping fruit size QTL, suggesting conserved function of FW2.2 in eggplant and pepper (Chaim et al. 2001; Doganlar et al. 2002). Additionally, a FW2.2/CNR family member in avocado may control fruit size by regulating cell proliferation (Dahan et al. 2010). Plant organ size in general is likely regulated by $C N R$ genes. For example, the search for $F W 2.2$ members in maize led to the identification of a family of $13 C N R$ genes. Two of them, ZmCNR1 and ZmCNR2, were shown to alter organ size (Guo et al. 2010). Over-expression of ZmCNR1 resulted in a reduction of the overall plant stature, highlighting that it acts as a negative cell number regulator in multiple tissues; $Z m C N R 2$ expression level was negatively correlated with cell production, even though transgenic lines over-expressing ZmCNR2 did not result in a phenotype (Guo et al. 2010). Another $F W 2.2$ family member regulates root nodule organogenesis in soybean (Libault et al. 2010). The expression of the soybean FWL1 (fw2.2-like 1) is induced in root hair cells during nodulation and its silencing results in a reduction of nodule number, suggesting that $F W L 1$ acts as an initiator of organ development as a result of cell proliferation.

Some members of the $F W 2.2 / C N R$ family are known to encode plasma membrane-bound proteins, showing common features in their tertiary structure which is made up of one or two trans-membrane helices surrounded by a cysteine- and proline-rich domain. They include proteins involved in the transport of metal cations through the plasma membrane, such as the cadmium transporters PCR and the calcium channels MCA. Similar to other known metal transporters, they act as homo-oligomers forming a complex able to bind and transport divalent cations (Song et al. 2010; Kurusu et al. 2012). The tobacco (Nicotiana tabacum L.) MCA1 and MCA2 genes encode putative $\mathrm{Ca}^{2+}$-permeable channels involved in the response to mechanical stress. Interestingly, over-expression of NtMCA1 and NtMCA2 in tobacco cells resulted in a significant reduction of cell proliferation (Kurusu et al. 2012), an effect that can be considered similar to that observed for FW2.2- and ZmCNR1-over-expressing lines of tomato and maize, respectively. Interestingly, tomato FW2.2 is found at the plasma membrane even though a role in cation transport has not yet been demonstrated (Cong and Tanksley 2006). Based on this finding, it can be hypothesized that cell proliferation is induced by FW2.2/CNR members via a modulation of the intracellular calcium concentration acting as a second messenger in signal transduction pathways controlling the cell cycle. However, further studies are needed to elucidate the mechanism by which FW2.2/CNR members exert their function.

Amplification of the $C N R$ genes in the plant kingdom

PLAC8 domain-containing proteins are known in animals and a variety of other eukaryotes. However, in plants the number of family members is larger than in other organisms. Prunus contains 23 CNR genes, which is more than in maize (12 members) (Guo et al. 2010) and tomato (19 members). While it is possible that not all $C N R$ genes are correctly annotated, the high number in peach can be explained in part as a consequence of a series of recent tandem duplication events that produced a dense gene cluster on chromosome 1. Despite differences in plant gene copy numbers, the phylogenetic tree supports the hypothesis suggested by Guo et al. (2010) of a plant-specific expansion and radiation of $C N R$ genes. Even though statistical support for a single plant-only cluster is low, sequences from animals and fungi are confined to the left-upper part of the tree (Fig. 2). Therefore, while the $F W 2.2 / C N R$ gene family members might play a role within an ancient signal transduction pathway that evolved before the divergence of single- and multicellular organisms (Cong and Tanksley 2006), their duplication and diversification in plants may reflect the need to coordinate cell division activity within different tissues, organs and growth stages to a higher level of complexity than in animal and fungal systems.

\section{Evaluation of $C N R$ genes as candidates for known cherry fruit size QTL}

$F W 2.2 / C N R$ gene family members are likely to underlie fruit size variation in other domesticated plants, such as those found in the Rosaceae family. Scorza et al. (1991) compared large- and small-fruited peach varieties in terms of cell number and cell size; 
while cell sizes were similar among all cultivars, the large-fruited genotypes exhibited a higher number of cells at all developmental stages, suggesting that the main mechanism by which fruit size is determined is cell proliferation in the early stages of ovary development. Similarly, Olmstead et al. (2007) reported that differences in cherry fruit size associated with domestication and modern breeding are mainly due to increases in cell number rather than cell size. These findings support the hypothesis that $F W 2.2 / C N R$ genes could be involved in the control of fruit size in Prunus. A peach $C N R$ homolog, PpCNR12, localized in the cherry G2 QTL interval and the position was confirmed by mapping PavCNR12 in the $\mathrm{N} \times \mathrm{E}$ and $\mathrm{R} \times \mathrm{L}$ populations. The position of PavCNR12 was consistent with the high fruit size QTL LOD scores, even though the most significant markers for mesocarp cell number and fruit weight in some years were found for those that were located immediately upstream and downstream of PavCNR12. On the other hand, PavCNR12 is clearly the most significant marker associated with fruit size in the $\mathrm{R} \times \mathrm{L}$ population. This is despite the fact that the population is much smaller, yet the parents are more closely related to one another than in the $\mathrm{N} \times$ E population. Fruit size of sour cherry is also likely controlled by $\operatorname{PcrCNR} 12$ since a closely linked marker shows association with fruit size.

Because of the wider cross and likelihood of many minor QTL, and despite the large population size of 557 individuals in the $\mathrm{N} \times \mathrm{E}$ population, the number of recombinants within this short region was too low to conduct a high-resolution fine-mapping analysis of the QTL to a single gene. Nevertheless, further support for the role of PavCNR12 in controlling fruit size in both sweet cherry populations was demonstrated by the haplotypes that were found. Specifically, PavCNR121 was associated with the large-fruited QTL allele in both progenies and, conversely, PavCNR12-2 was consistently associated with a small-fruited allele. The third allele, PavCNR12-3, was associated with the least favorable QTL allele in the $\mathrm{N} \times \mathrm{E}$ progeny. It is thus possible that the PavCNR12 alleles differentially contribute to fruit size. Similar to the tomato $F W 2.2$, no differences in the protein-coding region were found among the three alleles. Thus, the proposed effect of the PavCNR12 alleles might depend on the regulation of expression. Consistent with this hypothesis, the highest variation in the sequences was found in the promoter regions.
The analysis of the G6 candidate gene, PavCNR20, supported the presence of a divergent allele in New York 54, differentiating this genotype from all the other tested cultivars. Accordingly, only New York 54 was found to bear the unfavorable QTL allele, supporting the notion that the favorable allele is fixed in cultivated varieties during the domestication process of this species. Analysis of a SSR marker in the same region suggested the presence of the same QTL in sour cherry as well. Further analyses are needed to ascertain whether PavCNR2O could actually be responsible for the QTL effect in both species. Nevertheless, if the favorable allele(s) is fixed in sweet cherry domesticated varieties, the practical importance of this QTL will be limited to populations derived from crosses with wild genotypes. In other words, PavCNR2O could be considered a gene associated with the domestication process.

\section{Enabling marker-assisted breeding}

The QTL on G2 is the most important QTL involved in the control of fruit size in modern cherry germplasm, explaining the highest portion of the phenotypic variation (Zhang et al. 2010; Dirlewanger et al. 2009). While definitive proof of whether PavCNR 12 controls fruit size awaits further experimentation, the co-localization of PavCNR12 with the G2 QTL peak and the association of its haplotypes with the QTL effects support the hypothesis that both PavCNR12 and $\operatorname{PcrCNR} 12$ control fruit size in sweet and sour cherry, respectively. Allelic variation at the cherry CNR12 locus can be used to select from sweet cherry $\mathrm{R} \times \mathrm{L}$ and $\mathrm{N} \times \mathrm{E}$ populations those individuals that are homozygous for the PavCNR12-1 allele, which showed a mean fruit weight 16 and $9 \%$ higher than the mean value for their respective entire populations. For sour cherry, selection against alleles 4, 6 and in particular allele 8 , and for allele 2 of marker G2SSR1566, should result in progeny exhibiting larger fruit size and flesh weight.

The fruit size allele on G6 is less important for sweet cherry breeding programs, as the favorable allele is fixed in the cultivated germplasm. On the other hand, this could be an important marker for sour cherry breeding, as several putative alleles were identified with a significant effect on fruit size, possibly originating from the undomesticated progenitor species, $P$. fruticosa. In particular, selection for 
allele 3 and against allele 4 of marker G6SSR2208 should yield progeny with larger fruit size and flesh weight.

In summary, genetic and sequence data suggested that two of the peach $C N R$ gene family members are excellent candidate genes for two fruit size QTL in sweet and sour cherry. The finding that the increase in fleshy ovary size in both tomato and cherry associated with domestication may be due to changes in members of the same ancestral gene family supports the notion that similar phenotypic changes exhibited by independently domesticated taxa may have a common genetic basis.

Acknowledgments This work was supported in part by grants from the USDA (NIFA-NRI 2008-02259 and NIFA-SCRI 2009-51181-05808). We thank the members of the International Peach Genome Initiative (IPGI) for early access to the draft peach genome sequence, and members of the Iezzoni and van der Knaap labs for help with cherry harvest and fruit weight evaluations. JA Campoy is holder of a postdoctoral fellowship from the 'Programa de Formación Postdoctoral de Personal Investigador' of the 'Fundación Séneca-Agencia de Ciencia y Tecnología de la Región de Murcia’, Spain.

Open Access This article is distributed under the terms of the Creative Commons Attribution License which permits any use, distribution, and reproduction in any medium, provided the original author(s) and the source are credited.

\section{References}

Alpert KB, Tanksley SD (1996) High-resolution mapping and isolation of a yeast artificial chromosome contig containing fw2.2: a major fruit weight quantitative trait locus in tomato. Proc Natl Acad Sci USA 93:15503-15507

Brewer MT, Moyseenko JB, Monforte AJ, van der Knaap E (2007) Morphological variation in tomato fruit: a comprehensive analysis and identification of loci controlling fruit shape and development. J Exp Bot 58:1339-1349

Cabrera A (2011) Genetic analysis and fruit weight QTL fine mapping in sweet cherry (Prunus avium L.). Dissertation, The Ohio State University

Cabrera A, Kozik A, Howad W, Arus P, Iezzoni A, van der Knaap E (2009) Development and bin mapping of a Rosaceae conserved ortholog set (COS) of markers. BMC Genomics 10:562

Cabrera A, Rosyara UR, De Franceschi P, Sebolt A, Sooriyapathirana SS, Dirlewanger E, Quero-Garcia J, Schuster M, Iezzoni AF, van der Knaap E (2012) Rosaceae conserved orthologous sequences marker polymorphism in sweet cherry germplasm and construction of a SNP-based map. Tree Genet Genomes 8:237-247

Causse M, Chaib J, Lecomte L, Buret M, Frédéric H (2007) Both additivity and epistasis control the genetic variation for fruit quality traits in tomato. Theor Appl Genet 115:429-442
Chaim AB, Paran I, Grube RC, Jahn M, van Wijk R, Peleman J (2001) QTL mapping of fruit-related traits in pepper (Capsicum annuum). Theor Appl Genet 102:1016-1028

Cong B, Tanksley SD (2006) FW2.2 and cell cycle control in developing tomato fruit: a possible example of gene cooption in the evolution of a novel organ. Plant Mol Biol 62:867-880

Cong B, Liu J, Tanksley SD (2002) Natural alleles at a tomato fruit size quantitative trait locus differ by heterochronic regulatory mutations. Proc Natl Acad Sci USA 99:13606-13611

Dahan Y, Rosenfeld R, Zadiranov V, Irihimovitch V (2010) A proposed conserved role for an avocado fw2.2-like gene as a negative regulator of fruit cell division. Planta 232:663-676

Dirlewanger E, Graziano E, Joobeur T, Garriga-Calderé F, Cosson P, Howad W, Arús P (2004) Comparative mapping and marker assisted selection in Rosaceae fruit crops. Proc Natl Acad Sci USA 101:9891-9896

Dirlewanger E, Claverie J, Iezzoni AF, Wünsch A (2009) Sweet and sour cherries: linkage maps, QTL detection and marker assisted selection. Plant Genet Genomics Crops Models 6:291-313. Springer, New York

Doganlar S, Frary A, Daunay MC, Lester RN, Tanksley SD (2002) Conservation of gene function in the Solanaceae as revealed by comparative mapping of domestication traits in eggplant. Genetics 161:1713-1726

Esteras C, Nuez F, Picó B (2011) Genetic diversity studies in Cucurbits using molecular tools. In: Wang Y, Behera TK (eds) Cucurbits: genetics, genomics and breeding in crop plants. Science Publishers Inc., Enfield

Frary A, Nesbitt TC, Frary A, Grandillo S, van der Knaap E, Cong B, Liu J, Meller J, Elber R, Alpert KB, Tanksley SD (2000) Fw2.2: A quantitative trait locus key to the evolution of tomato fruit size. Science 289:85-88

Galaviz-Hernandez C, Stagg C, de Ridder G, Tanaka TS, Ko MS, Schlessinger D, Nagaraja R (2003) Plac8 and Plac9, novel placental-enriched genes identified through microarray analysis. Gene 309:81-89

Gonzalo MJ, van der Knaap E (2008) A comparative analysis into the genetic bases of tomato varieties exhibiting elongated fruit shape. Theor Appl Genet 116:647-656

Grandillo S, Ku HM, Tanksley SD (1999) Identifying the loci responsible for natural variation in fruit size and shape in tomato. Theor Appl Genet 99:978-987

Guo M, Simmons CR (2011) Cell number counts-the fw 2.2 and CNR genes and implications for controlling plant fruit and organ size. Plant Sci 181:1-7

Guo M, Rupe MA, Dieter JA, Zou J, Spielbauer D, Duncan KE, Howard RJ, Hou Z, Simmons CR (2010) Cell number regulator 1 affects plant and organ size in maize: implications for crop yield enhancement and heterosis. Plant Cell 22:1057-1073

Hammer K (1984) The domestication syndrome (In German). Kulturpflanze 32:11-34

Illa E, Sargent DJ, Lopez Girona E, Bushakra J, Cestaro A, Crowhurst R, Pindo M, Cabrera A, Van der Knapp E, Iezzoni A, Gardiner S, Velasco R, Arus P, Chagné D, Troggio M (2011) Comparative analysis of rosaceous genomes and the reconstruction of a putative ancestral genome for the family. BMC Evol Biol 11:9 
Jung S, Jiwan D, Cho I, Lee T, Abbott A, Sosinski B, Main D (2009) Synteny of Prunus and other model plant species. BMC Genomics 10:76

Klagges C, Campoy JA, Quero-García J, Guzman A, Mansur L, Gratacós E, Silva H, Rosyara UR, Iezzoni A, Meisel L, Dirlewanger E (2013) Construction and comparative analyses of highly dense linkage maps of two sweet cherry intra-specific progenies of commercial cultivars. PLoS ONE 8(1):e54743. doi:10.1371/journal.pone.0054743

Kurusu T, Yamanaka T, Nakano M, Takiguchi A, Ogasawara Y, Hayashi T, Iida K, Hanamata S, Shinozaki K, Iida H, Kuchitsu K (2012) Involvement of the putative $\mathrm{Ca}^{2+}$-permeable mechanosensitive channels, NtMCA1 and NtMCA2, in $\mathrm{Ca}^{2+}$ uptake, $\mathrm{Ca}^{2+}$-dependent cell proliferation and mechanical stress-induced gene expression in tobacco (Nicotiana tabacum) BY-2 cells. J Plant Res 125:555-568

Lee SH, Walker DR, Cregan PB, Boerma HR (2004) Comparison of four flow cytometric SNP detection assays and their use in plant improvement. Theor Appl Genet 110:167-174

Libault M, Zhang XC, Govindarajulu M, Qiu J, Ong YT, Brechenmacher L, Berg RH, Hurley-Sommer A, Taylor CG, Stacey G (2010) A member of the highly conserved $F W L$ (tomato FW2.2-like) gene family is essential for soybean nodule organogenesis. Plant J 62:852-864

Liu J, Cong B, Tanksley SD (2003) Generation and analysis of an artificial gene dosage series in tomato to study the mechanisms by which the cloned quantitative trait locus fw2.2 controls fruit size. Plant Physiol 132:292-299

Martins WS, Lucas DC, Neves KF, Bertioli DJ (2009) WebSat-a web software for microsatellite marker development. Bioinformation 3:282-283

Meyer RS, Karol K, Little DP, Nee MH, Litt A (2012) Phylogeographic relationships among Asian eggplants and new perspectives on eggplant domestication. Mol Phylogenet Evol 63:685-701

Miller AJ, Gross BL (2011) From forest to field: perennial fruit crop domestication. Am J Bot 98:1389-1414

Nuñez-Palenius HG, Gomez-Lim M, Ochoa-Alejo N, Grumet R, Lester G, Cantliffe DJ (2008) Melon fruits: genetic diversity, physiology, and biotechnology features. Crit Rev Biotechnol 28:13-55

Olmstead JW, Iezzoni AF, Whiting MD (2007) Genotypic differences in sweet cherry fruit size are primarily a function of cell number. J Am Soc Hort Sci 132:697-703

Olmstead JW, Sebolt AM, Cabrera A, Sooriyapathirana SS, Hammar S, Iriarte G, Wang D, Chen CY, van der Knaap E, Iezzoni AF (2008) Construction of an intra-specific sweet cherry (Prunus avium L.) genetic linkage map and synteny analysis with the Prunus reference map. Tree Genet Genomes 4:897-910

Paran I, van der Knaap E (2007) Genetic and molecular regulation of fruit and plant domestication traits in tomato and pepper. J Exp Bot 58:3841-3852

Paris HS, Lebeda A, Křistkova E, Andres TC, Nee MH (2012) Parallel evolution under domestication and phenotypic differentiation of the cultivated subspecies of Cucurbita pepo. Econ Bot 66:71-90

Peace C, Bassil N, Main D, Ficklin S, Rosyara UR, Stegmeir T, Sebolt A, Gilmore B, Lawley C, Mockler TC, Bryant DW, Wilhelm L, Iezzoni A (2012) Development and evaluation of a genome-wide $6 \mathrm{~K} \mathrm{SNP}$ array for diploid sweet cherry and tetraploid sour cherry. PLoS ONE 7(12):e48305. doi: 10.1371/journal.pone.0048305

Rozen S, Skaletsky HJ (2000) Primer3 on the WWW for general users and for biologist programmers. In: Krawetz S, Misener $S$ (eds) Bioinformatics methods and protocols: methods in molecular biology. Humana Press, Totowa, NJ, pp 365-386

Schuelke M (2000) An economic method for the fluorescent labeling of PCR fragments. Nat Biotechnol 18:233-234

Scorza R, May LG, Purnell B, Upchurch B (1991) Differences in number and area of mesocarp cells between small- and large-fruited peach cultivars. J Am Soc Hort Sci 116: $861-864$

Solovyev VV, Shahmuradov IA (2003) PromH: promoters identification using orthologous genomic sequences. Nucleic Acids Res 31:3540-3545

Song WY, Martinoia E, Lee J, Kim D, Kim DY, Vogt E, Shim D, Choi KS, Hwang I, Lee Y (2004) A novel family of cysrich membrane proteins mediates cadmium resistance in Arabidopsis. Plant Physiol 135:1027-1039

Song W-Y, Choi KS, Kim DY, Geisler M, Park J, Vincenzetti V, Schellenberg M, Kim SH, Lim YP, Noh EW, Lee Y, Martinoia E (2010) Arabidopsis PCR2 is a zinc exporter involved in both zinc extrusion and long-distance zinc transport. Plant Cell 22:2237-2252

Tamura K, Peterson D, Peterson N, Stecher G, Nei M, Kumar S (2011) MEGA5: molecular evolutionary genetics analysis using maximum likelihood, evolutionary distance, and maximum parsimony methods. Mol Biol Evol 28:2731-2739

Tanksley SD (2004) The genetic, developmental, and molecular bases of fruit size and shape variation in tomato. Plant Cell 16:S181-S189

Temnykh S, DeClerck G, Lukashova A, Lipovich L, Cartinhour S, McCouch S (2001) Computational and experimental analysis of microsatellites in rice (Oryza sativa L.): frequency, length variation, transposon associations, and genetic marker potential. Genome Res 11:1441-1452

Van Ooijen JW, Voorrips RE (2002) Joinmap 3.0, Software for the calculation of genetic linkage maps. Plant Research International, Wageningen

Wang D, Karle R, Iezzoni AF (2000) QTL analysis of flower and fruit traits in sour cherry. Theor Appl Genet 100:535-544

Wang JX, Gao TG, Knapp S (2008) Ancient Chinese literature reveals pathways of eggplant domestication. Ann Bot 102:891-897

Whiting MD, Ophardt D, McFerson JR (2006) Chemical blossom thinners vary in their effect on sweet cherry fruit set, yield, fruit quality, and crop value. HortTechnology 16:66-70

Yamanaka T, Nakagawa Y, Mori K, Nakano M, Imamura T, Kataoka H, Terashima A, Iida K, Kojima I, Katagiri T, Shinozaki K, Iida H (2010) MCA1 and MCA2 that mediate $\mathrm{Ca}^{2+}$ uptake have distinct and overlapping roles in Arabidopsis. Plant Physiol 152:1284-1296

Zhang G, Sebolt A, Sooriyapathirana S, Wang D, Bink M, Olmstead J, Iezzoni A (2010) Fruit size QTL analysis of an $\mathrm{F}_{1}$ population derived from a cross between a domesticated sweet cherry cultivar and a wild forest sweet cherry. Tree Genet Genomes 6:25-36 